\title{
História do Departamento de Biomecânica, Medicina e Reabilitação do Aparelho Locomotor da FMRP-USP
}

\author{
Cláudio Henrique Barbieri \\ Docente. Departamento de Biomecânica, Medicina e Reabilitação do Aparelho Locomotor. Faculdade de Medicina de Ribeirão Preto - USP
}

$\mathrm{O}$ Departamento de Ortopedia da Faculdade de Medicina de Ribeirão Preto foi fundado pelo Professor José Paulo Marcondes de Souza, em abril de 1958. Ao fazê-lo, o Prof. Marcondes procurou basear-se na escola inglesa de ortopedia, recém-chegado que estava de sua viagem de estudos a Oxford, sob os auspícios do British Council. Acabara, então, de estagiar com o Professor José Trueta, insigne professor espanhol, que galgou todos os postos da carreira universitária na multicentenária universidade daquela cidade, chegando a chefe do Departamento de Ortopedia, no Nuffield Orthopaedic Center. O Prof. Trueta havia ganho notoriedade mundial com a descrição da irrigação intraóssea e com os estudos sobre o desenvolvimento e a decadência do esqueleto humano, bem como sobre a fisiopatologia da osteomielite, doença de extrema importância na época dos primórdios da antibioticoterapia. O Prof. Marcondes foi grandemente influenciado pelo Prof. Trueta na sua formação médica, quer como clínico, quer como pesquisador, o que viria a ditar o modelo de pós-graduação por ele implementado anos mais tarde.

Ao fundar o Departamento de Ortopedia, o Prof. Marcondes não contava sequer com área física para iniciar o atendimento de seus pacientes, fazendo-o em pequena sala, gentilmente cedida pelos Professores Jorge Armbrust e Luiz Marino Bechelli, respectivamente, chefes dos Departamentos de Neuro- logia e Dermatologia. As operações ortopédicas foram viabilizadas graças à cessão de 3 leitos, pelo Professor Ruy E. Ferreira-Santos, chefe do Departamento de Cirurgia.

As atividades didáticas aos alunos do curso médico foram iniciadas quase de imediato, com a colaboração do Prof. Fernando Ferreira Machado, primeiro assistente do Prof. Marcondes, transferido do Departamento de Morfologia para o de Ortopedia, já a partir de agosto de 1958.

Apesar das dificuldades iniciais, o Prof. Marcondes estava imbuído do espírito de fundar uma nova escola ortopédica, interiorizando o ensino da Ortopedia e Traumatologia, então restrito a poucas capitais estaduais e à Capital Federal. Desse modo, novamente empreendeu viagem de estudos, entre outubro de 1959 e abril de 1960, desta vez a centros ortopédicos dos Estados Unidos da América do Norte, com bolsa de estudos da Fundação Rockefeller.

Pouco depois de seu retorno, o Departamento de Ortopedia obteve a contratação dos Professores Camilo André Mércio Xavier e Marcelo M. Moreira (MMM), em agosto de 1960, adicionada da contratação dos Professores Ricardo Fonseca Ribeiro (RFR), em fevereiro de 1961, e Luiz Gonzada Olivério (LGO), em julho de 1962.

Em agosto de 1961, com a inauguração do Hospital das Clínicas, no prédio da antiga Maternidade Sinhá Junqueira, que hoje alberga a Unidade de Emer- 
gência do HC, o Departamento de Ortopedia recebeu amplas enfermarias, totalizando 20 leitos, e salas de ambulatório, o que possibilitou seu primeiro surto de desenvolvimento, que incluiu a criação da Residência Médica (1963) e do Curso de Pós-Graduação Stricto Sensu (1974), fazendo-o ganhar rapidamente o reconhecimento nacional.

Com o passar dos anos, alguns professores do grupo inicial (MMM, RFR e LGO) deixaram o departamento, principalmente para se dedicarem a atividades privadas, mas outros os sucederam, como o Professor Gottfried Köberle (1968), Roberto Sérgio de Tavares Canto (1971), Andrés Edgar Rodriguez Fuentes (1974), Cláudio Henrique Barbieri (1975), Cleber Antônio Jansen Paccola (1976), José Batista Volpon (1978), Helton Luiz Aparecido Defino (1985), Nilton Mazzer (1986) e Celso Hermínio Ferraz Picado (1987). Desse grupo, apenas os dois primeiros desligaram-se da FMRP, para assumirem, respectivamente, a chefia do Departamento de Ortopedia e Traumatologia da UNICAMP, em 1975, e do Departamento de Traumatologia da Universidade Federal de Uberlândia, em 1976.

Esse novo grupo de docentes pode ser considerado o responsável pelo novo surto de desenvolvimento do Departamento, que incluiu a ampliação da Residência Médica em Ortopedia e Traumatologia e a criação da Residência Médica em Subespecialidades, como a Cirurgia da Mão e Microcirurgia, Ortopedia Infantil, Cirurgia da Coluna Vertebral, Cirurgia do Joelho e do Trauma, bem como a criação da área de Pós-Graduação em Bioengenharia, em associação com a Escola de Engenharia de São Carlos. Na atualidade, o grupo está envolvido com a criação dos cursos de graduação em Fisioterapia e Terapia Ocupacional da FMRP-USP.

Nesse contexto, a transferência do Hospital das Clínicas (HC) para sua sede própria, no Campus Universitário, em 1978, foi de fundamental importância para o progresso de todas as atividades do antigo departamento, depois denominado de Disciplina Ortopedia e Traumatologia, ligado ao Departamento de Cirurgia, Ortopedia e Traumatologia, por força da Reforma Universitária de 1970, doravante referido apenas como Departamento.

Em suas novas instalações, onde conta com 45 leitos, distribuídos em 12 enfermarias que ocupam todo o $11^{\circ}$ andar do HC, a disciplina pôde aumentar sobremaneira seu volume de atividades assistenciais, que propiciaram um aumento paralelo de suas atividades didáticas e de pesquisa. $\mathrm{O}$ número de pacientes atendidos anualmente, segundo dados de 1998, chega à média de 30.000 , que resultam em mais de 1.400 operações dos mais variados tipos, desde as mais simples até as mais complexas, sobre todos os segmentos do esqueleto humano, através das subespecialidades, sendo cerca de 1.000 realizadas com o paciente internado e 400 no Centro Cirúrgico Ambulatorial.

Depois da mudança do HC para sua sede própria, no Campus Universitário, o antigo prédio, comprado da Fundação Sinhá Junqueira, pelo Estado de São Paulo, foi transformado em Unidade de Emergência, com vistas a dar à cidade um pronto-socorro à altura das necessidades, frente ao crescente volume de traumatismos e urgências médicas. Tal fato só foi possível graças à adesão dos docentes dos departamentos de aplicação da FMRP, inclusive a Disciplina Ortopedia e Traumatologia, àquela idéia, cônscios que estavam da necessidade de manter, atualizar e aprimorar o ensino e a pesquisa sobre patologias traumáticas do aparelho locomotor. Naquela unidade, a Disciplina conta com apenas 10 leitos, mas responde pelo atendimento de cerca de 5.000 pacientes por ano, o que resulta num volume cirúrgico de cerca de 1.000 casos, a maioria complexos. O tratamento instituído nesses casos está à altura do que é feito de mais moderno, em nível mundial, o que tem feito da disciplina o grupo mais avançado do Brasil, nesse campo particular, inclusive porque o volume de atendimento global da disciplina, que chega a 35.000 , o que resulta em cerca de 2.400 procedimentos cirúrgicos, constitui-se num formidável laboratório de aplicação, propiciando o desenvolvimento de uma série de trabalhos, posteriormente publicados ou apresentados em congressos.

Paralelamente ao aumento quantitativo das atividades assistenciais, houve um progressivo aumento qualitativo, na medida em que os docentes da disciplina procuraram aperfeiçoar-se e adquirir novas tecnologias, principalmente através de viagens de estudo, em nível de pós-doutorado, a centros ortopédicos de grande expressão, em países como os Estados Unidos, Inglaterra, Alemanha, Itália, França e Suíça. Os novos conhecimentos adquiridos propiciaram que novas tecnologias pudessem ser introduzidas ou produzidas pelos próprios docentes, que criaram, assim, novas linhas de pesquisa de aplicação.

No que se refere às atividades didáticas, no Curso de Pós-Graduação Lato Sensu, já em 1978, a Disciplina ampliou o período mínimo de formação do médico residente, de 2 para 3 , numa iniciativa pionei- 
ra, que serviu de base para que a Sociedade Brasileira de Ortopedia e Traumatologia (SBOT), órgão que define, de fato, a formação dos ortopedistas brasileiros, passasse a exigir esse mesmo período de formação básica a todos os serviços especializados do Brasil. Mais recentemente, a partir de 1992, a Disciplina passou a oferecer treinamento avançado em várias de suas subespecialidades, que incluem a Cirurgia da Mão e do Membro Superior e Microcirurgia, Ortopedia Infantil, Cirurgia do Joelho e Traumatologia Ortopédica, Cirurgia da Coluna Vertebral, e Cirurgia do Quadril. Esse treinamento é aberto a um número ainda restrito de médicos residentes ou estagiários, já portadores do treinamento básico de 3 anos e que tenham sido aprovados no Exame Nacional para Obtenção do Título de Especialista, realizado anualmente pela SBOT.

No que se refere à pesquisa, tanto clínica, como experimental, ocorreu um grande salto em quantidade e qualidade, a partir da criação do Curso de Pós-Graduação stricto sensu, em Ortopedia e Traumatologia. A pesquisa experimental, acanhadamente praticada antes da década de 70, tornou-se uma exigência aos alunos desse curso, com base na certeza de que ela desenvolve seu espírito crítico e rigor científico. Já a pesquisa clínica, ou de aplicação, é, em geral, desenvolvida diretamente pelos docentes, a partir de sua atividade assistencial, cujo volume é adequado para que novas propostas de tratamento de problemas graves e difíceis sejam elaboradas e implementadas. Ambos os tipos de investigação científica têm sido objeto de considerável volume de publicações, em periódicos nacionais e estrangeiros, de grande impacto na comunidade ortopédica.

Nota-se, portanto, que a história do antigo Departamento de Ortopedia, depois, Disciplina de Ortopedia e Traumatologia e, hoje, Departamento de Biomecânica, Medicina e Reabilitação do Aparelho Locomotor*, foi e continua sendo a de um contínuo amadurecimento, que a guindou a lugar de destaque, tanto em nível nacional, como mundial, particularmente em alguns setores. Por força disso, laços científicos foram estabelecidos com algumas instituições internacionais, como o Orthopaedic Centre da Universidade de Pittsburgh, nos Estados Unidos, e a Funda- ção AO Internacional, na Suíça. Com a primeira, foi estabelecido um convênio de intercâmbio de informações e pesquisadores, em 1994, que propiciou, por enquanto, o envio de alunos do Curso de Graduação, para estágios curtos (01 a 02 meses), e de Pós-Graduação, para estágios mais longos (04 a 06 meses). Já com a segunda entidade, o convênio assinado em 1998 estabeleceu que a Disciplina será a primeira Clínica $\mathrm{AO}$ da América do Sul, situação que lhe permitirá adquirir materiais especiais de osteossíntese em condições economicamente vantajosas e em primeira mão, com a contrapartida de receber médicos do Brasil e do continente sul-americano para treinamento especializado, o que está em fase de implementação.

O hoje Departamento de Biomecânica, Medicina e Reabilitação do Aparelho Locomotor está envolvido em 2 programas de pós-graduação. O primeiro, a Área Ortopedia e Traumatologia da FMRP, estava destinado até 2 anos atrás somente a médicos com especialização em Ortopedia e Traumatologia, através da residência formal de 3 anos de duração, e portadores do título de especialistas, obtido da Sociedade Brasileira de Ortopedia e Traumatologia, por concurso. O segundo, o Curso de Pós-graduação Interunidades Bioengenharia - EESC/FMRP/IQSC-USP, criado em 1977, com o efetivo apoio da antiga Disciplina, está voltado para profissionais de outras áreas, tendo sido idealizado, inicialmente, para engenheiros, físicos e químicos, mas passando a receber, paulatinamente, outros profissionais de ciências biomédicas, como fisioterapeutas, terapeutas ocupacionais, biólogos e educadores físicos. Os fisioterapeutas representam, de fato, o maior contingente de alunos do curso na atualidade.

Indubitavelmente, o mais novo e, provavelmente, mais significativo marco na história aqui relatada, foi a criação, em outubro de 2000 , no bojo da reestruturação departamental da FMRP, do novo Departamento de Biomecânica, Medicina e Reabilitação do Aparelho Locomotor, mencionado acima. A criação do novo Departamento, coroou cerca de 12 anos de luta, e contou com a participação dos docentes das antigas Disciplinas de Ortopedia e Traumatologia e de Anestesiologia, originárias do antigo Departamento de Cirurgia, Ortopedia e Traumatologia, totalizando 13

\footnotetext{
* A denominação de Disciplina Ortopedia e Traumatologia refere-se à situação existente até outubro de 2000, quando foi criado o Departamento de Biomecânica, Medicina e Reabilitação do Aparelho Locomotor, constituído por aquela disciplina e pela Disciplina de Anestesiologia. Portanto, quando o evento relatado referir-se à época anterior a outubro de 2000 , a nomenclatura utilizada será a de disciplina e, para eventos posteriores àquela época, a nomenclatura empregada será a de departamento.
} 
docentes. O interesse na associação das 2 antigas Disciplinas deveu-se ao progressivo envolvimento científico entre elas, que já vinha desde cerca de 6 anos antes. De fato, no cotidiano, os docentes anestesistas sempre tiveram participação fundamental no desenvolvimento das atividades cirúrgicas dos docentes ortopedistas, que têm caráter tanto assistencial como de pesquisa, na maioria dos casos, e que também possibilitam a pesquisa aplicada de uma séria de procedimentos anestesiológicos. Tirante isso, a junção das 2 Disciplinas num departamento foi impulsionada pela existência de uma nova interface acadêmica e de pesquisa, que é a do estudo da dor, acometendo o Aparelho Locomotor. Desse envolvimento, originaram-se 2 linhas de pesquisa conjuntas e bem definidas, que são: 1) Terapêutica da Dor Aguda, em procedimentos ortopédicos sob anestesia regional, e 2) Terapêutica e Prevenção da Dor Crônica Neuropática, em procedimentos ortopédicos. Essas linhas de pesquisa envolvem: 1) realização de projetos de pesquisa e trabalhos de investigação científica entre as 2 equipes (Ortopedia e Anestesia), 2) participação direta e formação de alunos de pós-graduação, 3) criação de convênios com instituições internacionais, como o estabelecido com o Professor Ricardo Plancarte, Presidente da Sociedad de Anestesia de Mexico, com a finalidade de realizar intercâmbio de alunos de pós-graduação e de especialização, e 4) publicações científicas em periódicos indexados, de forma regular e contínua.

A antiga Disciplina de Anestesiologia, do antigo Departamento de Cirurgia da FMRP, depois Departamento de Cirurgia, Ortopedia e Traumatologia, foi fundada pelo Prof. Rubens Lisandro Nicoletti, em 1956, a convite do Prof. Ruy Escorel Ferreira-Santos, fundador daquele Departamento e seu chefe por mais de 20 anos. O Prof. Nicoletti contou com a participação, quase desde o início, dos Profs. Paulo de Mello Soares e Maricô Costa Pereira; juntos, montaram a estrutura que perdura até hoje, da qual faz parte o Serviço de Anestesiologia do HCFMRP-USP, sempre sob a chefia de um dos docentes atuais. O atual grupo de docentes anestesistas está constituído pelos
Profs. Marlene Paulino dos Reis e Anita Leocádia de Mattos, admitidas ainda na década dos anos 70, e Jyrson Guilherme Klamt, Luis Vicente Garcia e Gabriela Rocha Lauretti, admitidos na década de 80. As atividades dos docentes da antiga Disciplina concentram-se no Serviço de Anestesiologia, responsável por cerca de 16.000 procedimentos anestésicos dos mais variados portes, por ano, volume que se constitui num verdadeiro laboratório, pois permite a introdução de um grande número de novas técnicas e medicamentos, cujo real desempenho só é possível de ser avaliado, na situação de fato, em humanos. Além disso, os docentes da Anestesiologia têm introduzido técnicas anestesiológicas específicas para procedimentos cirúrgicos de alta complexidade, como as cirurgias cardíacas, cirurgias pediátricas, cirurgias de transplante (renal, hepático, etc), neurocirurgias, inclusive a cirurgia da epilepsia, e outros. Essa atividade permite a admissão anual, para treinamento especializado, de 15 médicos residentes.

Há cerca de 10 anos, os docentes da Anestesiologia passaram a desenvolver suas habilidades no manuseio e tratamento da dor aguda e crônica, criando a Clínica de Dor do HCFMRP, que passou a ser um centro de referência para essa atividade, permitindo o treinamento especializado de 2 médicos por ano e gerando considerável produção científica.

Além das atividades docentes de treinamento de residentes, os docentes da Anestesiologia dedicamse ao ensino de graduação, aos alunos do $4^{\circ}$. ano médico e do internato, e de pós-graduação. Esta última foi desenvolvida até o final do ano 2000 junto ao Programa de Pós-graduação em Clínica Cirúrgica da FMRP, tendo titulado 17 alunos, sendo nove no Curso de Mestrado e oito no de Doutorado, incluindo o atual grupo de docentes anestesistas, hoje atuando como orientadores. As atividades de ensino de pós-graduação da Anestesiologia estão sendo transferidas para o novo Departamento e para o Programa de Pós-Graduação em Ortopedia e Traumatologia, cuja ampliação está sendo presentemente proposta, como ficou explícito neste texto. 